\title{
A ANÁLISE CRÍTICA DO DISCURSO COMO ALTERNATIVA TEÓRICO- METODOLÓGICA PARA OS ESTUDOS ORGANIZACIONAIS: UM EXEMPLO DA ANÁ- LISE DO SIGNIFICADO REPRESENTACIONAL
}

\author{
Critical Discourse Analysis as a theoretical-methodological alternative for \\ organizational studies: an example of representational meaning analysis
}

Helena Kuerten de Salles*

Eloise Helena Livramento Dellagnelo**

\section{RESUMO}

A Análise Crítica do Discurso (ACD) é uma alternativa teórico-metodológica para os estudos organizacionais críticos já que ela contribui para o exame de questões sociais do mundo contemporâneo e busca desnaturalizar crenças que servem de suporte às estruturas de dominação. Embora a adoção da ACD na Administração não seja nova, seu uso ainda é restrito e a análise da dimensão textual nem sempre tem sido explorada em profundidade. Assim, neste trabalho, recuperamos os pressupostos teóricos e metodológicos da abordagem de ACD de Norman Fairclough (1989, 2001,2003 ) bem como fornecemos subsídios para a análise da dimensão representacional, exemplificando sua operacionalização. Com isso, procuramos elucidar aspectos relacionados à análise linguística dos textos com vistas a disseminar a abordagem entre pesquisadores do campo.

Palavras-chave: Análise Crítica do Discurso. Estudos Organizacionais. Análise textual. Significado Representacional.

\begin{abstract}
Critical Discourse Analysis (CDA) is a theoretical-methodological alternative for critical organizational studies because it contributes to the examination of social issues in the contemporary world and seeks to denaturalize beliefs that support the structures of domination. Although the adoption of the CDA in the Administration area is not new, its use is still restricted, and the analysis of the textual dimension has not always been explored in depth. Thus, in this article, we retrieve the theoretical and methodological bases of Norman Fairclough's approach (1989, 2001, and 2003) and also provide subsidies to operationalize analytical categories of representational meaning, exemplifying its operationalization. With this, we seek to elucidate aspects related to the linguistic analysis of the texts in order to disseminate the approach among researchers in the area.
\end{abstract}

Keywords: Critical Discourse Analysis. Organizational Studies. Textual analysis. Representational Meaning.

\footnotetext{
* Doutora em Administração pela Universidade Federal de Santa Catarina (UFSC). Professora do Curso de Administração da Universidade Federal de Santa Catarina (UFSC) - Florianópolis (SC), Brasil. E-mail: ahelena.salles@ufsc.br. ORCID: 0000-0002-7453-3219

** Doutora em Engenharia de Produção pela Universidade Federal de Santa Catarina (UFSC). Professora do Programa de Pós-Graduação em Administração da Universidade Federal de Santa Catarina (UFSC) - Florianópolis (SC), Brasil. E-mail: eloise.livramento@ufsc.br. ORCID: 0000-0001-7586-0302
} 


\section{INTRODUÇÃO}

O s estudos organizacionais que se caracterizam por uma abordagem crítica, quer sejam tributários da teoria crítica, segundo a tradição da Escola de Frankfurt; teoria crítica em estudos organizacionais; critical management studies ou análises críticas em estudos organizacionais (FARIA, 2009) utilizam diversas bases teóricas e metodológicas de suporte em suas argumentações. Com base em levantamento bibliográfico feito, observamos que há um número ainda limitado, porém crescente de publicações em periódicos nacionais na área da Administração que discutem criticamente fenômenos sociais diversos apoiados na abordagem da Análise Crítica do Discurso.

A Análise Crítica do Discurso (ACD) é uma alternativa teórico-metodológica para os estudos organizacionais críticos já que ela contribui para o exame de questões sociais do mundo contemporâneo e busca desnaturalizar crenças que servem de suporte às estruturas de dominação. A ACD se consolidou no início da década de 1990, na área de conhecimento da Linguística, e podemos reconhecer duas principais tradições, os franceses, cujas importantes referências são Michel Pêcheux, Dominique Maingueneau e no Brasil, Eni Orlandi; e os anglo-saxões, que tem como alguns nomes de destaque Norman Fairclough, Teun van Dijk, Ruth Wodak, Guinter Kress, Roger Fowler, Theo van Leeuven e, no Brasil, Izabel Magalhães, Viviane Resende e Viviane Ramalho.

Em comum ambas as correntes não tratam tão somente da língua, mas tratam do que fazemos por meio da linguagem (relações de poder, moldagem de identidades sociais etc.). No entanto, distanciam-se em outros pontos, como na própria operacionalização da análise. A abordagem anglo-saxã, que exploraremos neste artigo, tem em seu cerne análises textuais detalhadas, fundamentando-se na Linguística Sistêmico-Funcional (HALLIDAY, 2004). Assim, acreditamos que uma aproximação mais precisa e detalhada da operacionalização da ACD pode ajudar sobremaneira pesquisadores da área de estudos organizacionais a adotá-la em seus trabalhos. Deste modo, nosso objetivo é recuperar os pressupostos teóricos e metodológicos da Análise Crítica do Discurso proposta por Norman Fairclough (1989, 2001, 2003), exemplificando a operacionalização de categorias analíticas do significado representacional. Destacamos que, embora Fairclough ofereça recursos metodológicos para explorar os três significados da linguagem (acional, representacional e identificacional) apresentados por ele, para fins de análise o autor afirma que se pode privilegiar o significado da linguagem mais relevante ao interesse de pesquisa. Neste sentido, sendo a ACD uma abordagem ampla, neste artigo privilegiamos o significado representacional cujo potencial de análise oferece recursos metodológicos para explorar como aspectos do mundo (físico e social) são representados/recriados nos textos.

Nossa proposta diverge da maioria dos artigos publicados na área uma vez que a adoção da ACD não é nova, mas a análise da dimensão textual nem sempre tem sido explorada em profundidade em nossa área. De acordo com o levantamento dos artigos publicados em periódicos indexados no Scientific Periodicals Electronic Library (Spell) até 2016, identificamos 23 trabalhos que recorreram a Análise Crítica do Discurso da corrente anglo-saxã, seja para discutir diversos temas ligados aos estudos organizacionais, ou mesmo para explorar teoricamente a própria abordagem. 
Deste inventário, observamos que 21 trabalhos recorreram à ACD como método de análise, ou seja, utilizaram a abordagem para sustentar e discutir os dados da pesquisa. Dentre os quais verificamos um grupo de artigos que focam as relações de trabalho (SILVA; COSTA; LEMOS, 2015; ONUMA; ZWICK; BRITO, 2015; COSTA; BARROS; MARTINS, 2012; DOURADO; CARVALHO, 2007); um conjunto de artigos que recorrem à ACD para discutir aspectos que circundam a Administração Pública (MACEDO; ALCÂNTARA; PERElRA, 2015; CUNHA; COELHO; POZZEBON, 2014; BRETAS; SARAIVA, 2014; LACERDA; BRULON, 2013; ROSA FILHO, 2011; MISOCZKY; FERREIRA, 2005); outros recorreram à ACD para analisar o papel de organizações internacionais (MISOCZKY, 2003; MELO; SALLES; VAN BELLEN, 2012); e ainda outros trabalhos que elegeram temas diversos, mas unidos pela crítica (AGUIAR; CARRIERI, 2016; FREITAS et al, 2016; CARRIERI; SOUZA; AGUIAR, 2014; SALLES et al, 2011; AUGUSTINIS; COSTA; BARROS, 2012; VALADÃO JUNIOR; MEDEIROS; LIMA, 2007; BORGES; VALADÃO JÚNIOR, 2008; SCHARF; SARQUIS, 2014; FRANCO; LEÃO, 2014).

Destacamos que esses trabalhos que utilizaram a ACD como método de análise de dados não esclarecem em detalhes a operacionalização da metodologia, ou seja, mantém o foco nos resultados da pesquisa e menos na operacionalização do método. Assim, não servem como uma referência didática a leitores que queiram se apropriar da ACD. Além destes 21 trabalhos empíricos, localizamos no levantamento, dois artigos que exploraram a ACD teoricamente (RODRIGUES; DELLAGNELO, 2013; MISOCZKY, 2005). Esses, apesar de aprofundarem a discussão da abordagem, não enfatizam a exemplificação de categorias analíticas propostas na abordagem.

Nesse sentido, diferentemente da maioria dos artigos publicados na área que adotam a ACD para explorar os dados da pesquisa, nesse artigo fizemos o processo inverso: usamos os resultados de uma pesquisa para ilustrar como operacionalizar a ACD, especificamente o significado representacional. Esta pesquisa, que ilustra nossos exemplos, objetivou analisar como a avaliação de desempenho de organizações da sociedade civil é representada por atores do próprio campo associativista. Nosso corpus revelou que o terceiro setor e o gerencialismo são os discursos dominantes quando a questão é avaliar o que é desejável e pertinente, ou não, em uma organização, mesmo sendo ela uma organização da sociedade civil. Isso é afirmado com base na extensa análise linguística realizada e que será parcialmente mostrada nesse artigo a fim de ilustrar a operacionalização da ACD.

Por fim, destacamos que este artigo foi organizado em cinco seções: além desta introdução, na qual enfatizamos a contribuição do trabalho para área, na seção dois discutiremos a base teórica da abordagem da ACD neste caso específico; na seção três traremos o aparato metodológico da ACD; na seção quatro apresentamos especificamente a operacionalização do método; e, por fim, na seção cinco concluímos destacando o potencial da abordagem para os estudos organizacionais críticos.

\section{PRESSUPOSTOS TEÓRICOS DA ANÁLISE CRÍTICA DO DISCURSO}

A ACD busca superar uma lacuna entre teorizações baseadas na linguagem e pesquisas voltadas para uma explanação do papel da linguagem em práticas sociais contextualizadas. Para isso, sustenta uma teorização complexa sobre a relação entre discurso e 
estruturas sociais e conta com um amplo suporte teórico das Ciências Sociais (de Antonio Gramsci apropria-se da noção de hegemonia; de John Thompson o entendimento de ideologia; do materialismo histórico de David Harvey (2003) a ideia de práticas sociais; do sociólogo Anthony Giddens recorre à noção de estrutura social; de Mikhail Bakhtin busca as teorizações de intertextualidade; Michel Foucault exerce uma importante influência sobre o conceito de discurso; de Jürgen Habermas trabalha a ideia de colonização dos e pelos discursos; entre outros). Ao delimitar o conceito de discurso, portanto, Fairclough procurou combinar a abordagem linguística com uma perspectiva socioteórica de discurso. (FAIRCLOUGH, 2001, p. 22)

Essa aproximação sociolinguística parte do pressuposto que o discurso (manifestações linguísticas verbais e não-verbais) é um elemento inerente a todas as práticas sociais. Sobre práticas sociais, Fairclough (2001) esclarece que a vida social é uma rede interconectada de diferentes práticas sociais e cada prática (como ensino nas salas de aula, refeições em família, consultas médicas etc.) é resultante da combinação entre alguns elementos sociais.

Para Chouliaraki e Fairclough (1999, p. 21) as práticas sociais são "[...] maneiras habituais, em tempos e espaços particulares, pelas quais pessoas aplicam recursos - materiais ou simbólicos - para agirem juntas no mundo". Para os autores qualquer prática social é composta dos seguintes elementos: discurso (ou semiose); atividade material (objetos e artefatos físicos); relações sociais (relações de poder e luta hegemônica pelo estabelecimento, manutenção e transformação dessas relações); e fenômeno mental (crenças, valores, ideologia).

Na perspectiva da ACD situar o discurso com um momento de qualquer prática social tem, pelo menos, três implicações. Primeiro, significa assumir que a linguagem não é uma atividade puramente individual, mas que os indivíduos realizam ações por meio da linguagem, ou seja, através da linguagem as pessoas agem sobre o mundo, e sobre as outras pessoas. Segundo, existe uma relação bidirecional entre discurso e estrutura social, o que faz com que alguns discursos sejam aceitos em determinados contextos e rejeitados em outros, por exemplo. Por fim, a terceira implicação, de conceber o discurso como um elemento da prática social é reconhecer que não são apenas os recursos cognitivos dos indivíduos que atuam na elaboração ou apreensão de textos, mas, sobretudo, os sociocognitivos. A dimensão sociocognitiva está envolvida tanto na produção quanto na interpretação textual, expressando recursos interiorizados do contexto social do qual o produtor/interpretador faz parte, interferindo no texto e deixando pistas para análise de aspectos ideológicos (FAIRCLOUGH, 2001, p. 109). O sentido desta ideia se amplia se entendermos que o processo de fala (ou escrita) envolve a seleção de palavras, dentre um conjunto finito de opções oferecido pelo sistema gramatical, para significar aquilo que desejamos expressar num determinado contexto. Esta seleção de palavras revela importantes questões sobre o contexto em que foram geradas e a visão de mundo que está sendo (re)produzida.

Deste feito, o texto (entendido como o produto da interação), embora produzido por um indivíduo, é gerado a partir da ordem do discurso (permissões e restrições discursivas de um dado contexto social), ou seja, contém vestígios desse contexto e, por isso, ajudam a descortinar estruturas sociais abstratas nas quais estamos imersos. 
Para Fairclough (2001) ao se expor as ideologias subjacentes a um discurso contribui-se para conscientizar as pessoas de que nem todo senso comum é natural, mas sim naturalizado por tradições e convenções sociais que, normalmente, perpetuam relações assimétricas de poder. Dessa forma, quando as práticas discursivas são percebidas como construções sociais podem ser questionadas e perder sua força de sustentar práticas sociais centradas na desigualdade.

A esta altura, podemos observar que na ACD o termo discurso não apenas é fundante, como também é usado com significados distintos. Conforme pontuado por Meurer (2005, p. 87), o termo discurso guarda certa ambivalência, pois "[...] por um lado tem um significado muito próximo de ideologia e por outro é apenas uma ocorrência de uso da linguagem [...]". Na explicação de Brandão (2004) o discurso é o ponto de conexão dos processos ideológicos e dos fenômenos linguísticos. Conforme a autora

A linguagem enquanto discurso não constitui um universo de signos que serve apenas como instrumento de comunicação ou suporte de pensamento; a linguagem enquanto discurso é interação, e um modo de produção social; ela não é neutra, inocente e nem natural, por isso o lugar privilegiado de manifestação da ideologia (BRANDÃO, 2004, p. 11).

Frente à colocação da autora, depreendemos que a noção de discurso em ACD implica outros dois conceitos: linguagem e ideologia. O discurso como linguagem (e outros tipos de semiose) está relacionado à ideia de língua em uso, configurando, portanto, um dos elementos constituintes de qualquer prática social. Já como um substantivo mais concreto, discurso significa modos particulares de representação da realidade, vinculando-se a noção de ideologia.

Para Fairclough (2001, p. 117) "[...] as ideologias são significações/construções da realidade que são construídas em várias dimensões das formas/sentidos das práticas discursivas e que contribuem para a produção, a reprodução ou a transformação das relações de dominação". No entanto, na clara posição do autor, o discurso tem orientação bidirecional e por isso as transformações sociais são possíveis. Isto significa dizer que os eventos discursivos são moldados pela estrutura social, refletindo códigos sociais, regras e convenções, mas também moldam as estruturas sociais. Assim, para Fairclough, a ideologia não opera somente na solidificação do hegemônico, ela também se faz presente, e talvez essa seja a aposta mais importante do autor, no discurso contra hegemônico pois é neste que está presente a possibilidade de mudança social.

$\mathrm{Na} A C D$, portanto, parte-se do princípio que ao utilizar a linguagem para interagir as pessoas não estão interessadas em produzir sons, palavras e frases, mas, sobretudo, em criar significados (EGGINS, 1994). Esta percepção está ancorada na Linguística Sistêmica Funcional (LSF) de Michael Halliday, que corresponde a base teórica linguística da ACD de Fairclough. Para Halliday (2004) o texto é um evento aberto, ou seja, ele interage com contexto da situação e da cultura em que está inserido. Esse pressuposto da LSF demonstra como uma teoria linguística pode explicar a relação dialética entre linguagem e sociedade e pode, portanto, ser uma importante abordagem teórico-metodológica para estudos organizacionais engajados no ato da denúncia (SANTOS, 2002), como relações de poder em organizações; efeitos da tecnologia na jornada de trabalho; efeitos do capitalismo sobre 
trabalhadores; efeitos do produtivismo sobre a saúde; as questões de gênero e poder nas organizações, entre tantas outras possibilidades.

\section{PRESSUPOSTOS METODOLÓGICOS DA ANÁLISE CRÍTICA DO DISCURSO}

A Análise Crítica do Discurso (ACD) desenvolvida por Norman Fairclough é uma abordagem de Análise do Discurso Textualmente Orientada (ADTO) que recorre à gramática funcionalista para compreender as estruturas linguísticas usadas como modo de ação sobre o mundo e sobre as pessoas. Isto significa que a análise textual é um momento imprescindível na ACD. Para Halliday (2004), uma análise do discurso não resguardada por evidências textuais é apenas uma opinião, ou seja, o texto é a evidência empírica da análise e confere rigor e cientificidade para as argumentações da/o pesquisadora/o.

A abordagem de ACD aqui apresentada, portanto, nos oferece recursos metodológicos para explorar ideologias subjacentes a linguagem textual (outras abordagens exploram outras formas da linguagem, como a multimodal, por exemplo).



Figura 1 - Etapas para constituição de um corpus.

O texto ou conjunto de textos que serão analisados constituem o corpus de análise. Para Fairclough (1989) a perspectiva do pesquisador é importante na seleção dos dados e na construção do corpus a ser usado e por isso é indispensável possuir domínio do contexto que se está pesquisando. Deste feito, em qualquer pesquisa apoiada na $A C D$, um primeiro passo é a aproximação com o fenômeno de análise. Somente o conhecimento teórico e empírico do fenômeno permitirá o/a pesquisador/a reconhecer textos relevantes para composição de um 
corpus sob pena, em caso contrário, de selecionar materiais insignificantes para análise do discurso do fenômeno em foco. Neste sentido, Fairclough (1989) assinala que um problema de ordem prática é saber que textos são uteis e como chegar até lá, para isso deve-se, preliminarmente, ter o domínio do que se está pesquisando para então decidir onde coletar o material para um corpus. Para exemplificar esta questão, explicamos na sequência como se deu o processo de constituição do corpus em uma pesquisa cujo proposto era discutir como a avaliação de desempenho de organizações sem fins lucrativos é representada por atores do campo associativista. Para compor um corpus representativo do fenômeno foi indispensável compreender a estruturação do próprio campo. Para isso, etapas distintas de aproximação foram adotadas, conforme ilustra a Figura 1.

Em pesquisas que se apoiam na ACD, além da constituição do corpus de análise, outra definição importante é quanto ao significado textual que será explorado, haja vista que, em função do interesse da pesquisa, pode-se eleger explorar um significado textual mais relevante. Quanto aos significados textuais, Fairclough (2003) assume que todo texto guarda simultaneamente três significados: acional, identificacional e representacional. Esses significados textuais correspondem a três funções que realizamos por meio da linguagem (1) ação, (2) representação de fenômenos do mundo físico e social e (3) identificação de nós mesmos e dos outros.

A escolha do significado textual que será explorado no corpus depende do objetivo da pesquisa em curso. Em pesquisas nas quais o que está em foco são as interações entre sujeitos, explorar o significado acional pode ser valioso. Segundo Fairclough (2003, p. 65), "[...] poderíamos dizer que a (inter)ação não é apenas discurso, mas frequentemente é principalmente discurso". Isso significa que as relações sociais são parcialmente discursivas e, portanto, os textos nos contam sobre as interações sociais e o caráter da relação estabelecida entre as pessoas, se simétrica ou assimétrica; de poder ou subordinação; cooperativa ou competitiva; próxima ou distante etc.

Desse modo, o significado acional focaliza o texto como modo de ação em eventos sociais, legitimando ou questionando as relações sociais. Com isso, discutir como as pessoas agem e interagem por meio da linguagem pode revelar as posições dos sujeitos na atividade em curso, indicando, por exemplo, relações assimétricas de poder.

O discurso também age como um elemento na constituição de modos particulares de ser. Como explica Fairclough (2003, p.159) “[...] quem você é, é parcialmente uma questão de como você fala, como você escreve, bem como uma questão de corporificação como você se parece, como você se posiciona, como você se movimenta, e assim por diante". Deste modo, o significado identificacional é útil em pesquisas que buscam identificar como são construídas e negociadas identidades no texto, ou seja, como as pessoas identificam a si próprias, e identificam e são identificadas por outros. O significado identificacional, portanto, não está relacionado apenas à identidade, mas também a identificação do outro e, por isso, relacionado a julgamentos (sujeito moral).

Por fim, apresentamos o significado representacional, que além de suas características conceituais, demonstraremos na seção seguinte sua operacionalização. O significado representacional está relacionado a forma como aspectos do mundo físico e social estão representados em textos. Nesta perspectiva, importa notar que aspectos particulares do mundo podem ser representados de maneiras diversas e envolvem, em algum grau, aspec- 
tos ideológicos. Isso significa que diferentes discursos são diferentes perspectivas do mundo que estão associadas a diferentes relações que as pessoas estabelecem com o mundo e que estabelecem com outras pessoas (cooperação, competição, dominação etc.).

Diferentes discursos não apenas representam o mundo 'concreto', mas também projetam possibilidades diferentes da 'realidade', ou seja, engajam-se a projetos de mudança de acordo com perspectivas particulares. Portanto, os diferentes discursos podem se relacionar por complementaridade ou competindo em relações de dominação, já que o discurso constitui uma prática social através da qual os indivíduos agem no mundo. Isso confere aos discursos um caráter ambivalente, podem tanto servir de prática ideológica quanto emancipatória. A operacionalização deste significado é explorada na seção seguinte.

\section{OPERACIONALIZANDO A ANÁLISE TEXTUAL DO SIGNIFICADO REPRESENTACIONAL}

Nesta seção é apresentada a operacionalização de categorias de análise do significado representacional. Para isso, apresentamos teoricamente tais categorias e na sequência ilustramos com exemplos. Os exemplos apresentados são oriundos do corpus de uma pesquisa teórica-empírica na qual analisamos como atores do campo associativista representam a avaliação de desempenho de organizações sem fins lucrativos, buscando localizar discursos potencialmente ideológicos. Os resultados dessa pesquisa evidenciaram que os próprios atores do campo reproduzem o discurso do terceiro setor e o discurso gerencialista, e revelaram que há resistência ao discurso genuíno das organizações sem fins lucrativos.

Para compreender o que esses resultados significam é indispensável, conforme mencionado na seção três, possuir domínio do contexto que se está pesquisando. Isso significa afirmar que o/a pesquisador/a deve compreender densamente a temática de pesquisa para conseguir reconhecer discursos presentes no corpus em análise. Neste sentido, sobre os discursos identificados na pesquisa que ilustra os exemplos desse artigo, segue uma breve contextualização.

Segundo Montaño (2010) o discurso do terceiro setor, terminologia largamente adotada para referir-se ao universo do associativismo civil, representa uma estratégia do capital para legitimar as organizações sem fins lucrativos como a alternativa de lidar com a questão social, sob a justificativa de que o Estado é incapaz, pois demasiadamente burocrático e estas são supostamente mais ágeis e eficientes. A partir da legitimação do discurso de que o terceiro setor, as organizações sem fins lucrativos têm sido acometidas por parte de diversos segmentos da sociedade para que produzam resultados positivos. Dessa maneira, o discurso gerencialista se consolida já que ele justifica a aplicação de técnicas de gestão para todas as áreas da sociedade com base numa ideologia superior, formação especializada e detenção exclusiva do conhecimento gerencial necessário para administrar com eficiência empresas e sociedade (KLIKAUER, 2015). Na medida em que o discurso do terceiro setor e do gerencialismo se disseminam no campo associativista, são silenciadas características genuínas desse campo, como solidariedade, julgamento ético, engajamento voluntário.

Tendo esse corpo teórico como pano de fundo é possível partir para análise textual. Para iniciá-la não há necessidade de fixar previamente as categorias linguísticas que serão 
adotadas para análise. Isso porque não há como saber de antemão quais recursos linguísticos estarão presentes com maior ou menor intensidade no corpus.

A análise textual deve envolver, inicialmente, uma análise interna do texto a qual pode incluir a verificação de relações semânticas (causais, condicionais, temporais, aditivas, elaborativas, contrastes); relações gramaticais (conjunções, proposições, inserções); e vocabulário. No entanto, a análise interna não é útil por si só. Essa primeira aproximação com o texto deve ser realizada buscando explicar o significado que as características gramaticais identificadas no texto exercem no contexto da prática discursiva.

Um segundo momento da análise textual envolve a análise das relações externas do texto, ou seja, o exame da relação do texto com outros textos. Uma primeira categoria que contribui para a compreensão das relações externas é a intertextualidade.

\subsection{INTERTEXTUALIDADE}

Uma categoria que contribui para a compreensão das relações externas estabelecidas num texto é a análise da relação do texto com outros textos, buscando identificar como os elementos de outros textos são incorporados no texto em análise, ao que Fairclough (2003) denomina de intertextualidade.

A análise da intertextualidade é particularmente importante para observar como o texto se relaciona com repertórios socialmente disponíveis (FAIRCLOUGH, 2003). A citação é a forma de intertextualidade mais evidente, sobretudo, na forma direta na qual um texto externo é reportado conforme expresso e evidenciado por marcadores textuais como aspas ou recuo de texto. Há também a citação indireta na qual um texto é reportado e, embora mantenha o conteúdo, não é uma cópia literal do original.

Ainda em relação à intertextualidade, Fairclough (2003) associa este conceito à noção de pressuposto (assumptions). Segundo o autor, os textos, inevitavelmente, envolvem pressuposições já que o que é dito num texto sempre está relacionado àquilo que é tomado como dado pelo autor, que foi lido, pensado e/ou ouvido precedentemente. Dessa maneira, como uma das formas de intertextualidade, os pressupostos conectam um texto a outros textos, não a textos específicos, mas ao mundo dos textos.

Tanto a análise das citações como dos pressupostos contribui para verificar quais ideias são trazidas para o texto e de que forma são incorporadas. No entanto, uma marcante diferença é que enquanto a citação abre espaço para as diferenças, trazendo de forma mais explícita outras vozes para o texto, o pressuposto reduz as diferenças por assumir uma ideia como um fato dado. Assim, podemos dizer que a intertextualidade pode variar em termos de dialogicidade. Se tomarmos os textos como eventos sociais, podem-se diferenciar cinco possíveis cenários para a relação com outros textos (FAIRCLOUGH, 2003):

a) Abertura, aceitação, reconhecimento da diferença, exploração da diferença e como um diálogo;

b) Acentuação da diferença, conflito, polêmica, luta por significados, normas e poder; 
c) Tentativa de resolver e superar diferenças;

d) Suspensão das diferenças, foco na solidariedade e nos aspectos comuns;

e) Consenso, uma normalização e aceitação de diferenças de poder que suspendem ou suprimem diferenças de significados e normas.

Na opção mais dialógica as representações são explicitamente atribuídas a fontes, e se tenta incluir a variedade de vozes existentes e na forma menos dialógica de todas, estão os pressupostos, onde não há abertura para diferença. Entre esses dois extremos, há as afirmações modalizadas e as afirmações não modalizadas.

Em relação às afirmações, Halliday (2004) menciona que a polaridade é uma questão de escolha entre sim e não. Entretanto, estas não são as únicas possibilidades, há níveis intermediários entre estes polos positivos e negativos, ao que se denomina modalidade. 0 que o sistema de modalidade faz é interpretar a região de incerteza que se encontra entre o sim e o não. Dessa forma, por meio dessa análise podemos identificar o engajamento do enunciatário com aquilo que é afirmado. Esse engajamento varia, sendo as afirmações modalizadas uma forma de menor comprometimento do que as afirmações categóricas (ou não modalizadas). A modalidade, portanto, pode ser vista em termos do comprometimento que o enunciante assume com aquilo que diz em seu texto e está relacionado ao julgamento em relação ao que é verdadeiro e o que é necessário, ao que é desejável ou indesejável e revelam a forma como a realidade social é representada.

Segundo Halliday (2004), o que o sistema de modalidade faz é construir uma região de indeterminação que se encontra entre o sim e o não e ainda divide essa região em duas categorias: modalização e modulação, ao que Fairclough (2003) denomina de modalidade epistêmica e modalidade deôntica, respectivamente.

A modalidade epistêmica é usada para se referir sobre probabilidade (certo, provavelmente, eventualmente) ou frequência (sempre, usualmente, às vezes). Então, pode ser pensada como um recurso do sistema linguístico que aponta o grau de veracidade ou credibilidade que aferimos às nossas proposições sobre coisas do mundo. Já a modalidade deôntica designa obrigação (isto é, isto deve, será, pode ser, não é). Ela incita a ação e, portanto, pode ser pensada como um recurso de linguagem que aponta o comprometimento de um participante na realização de uma ação no mundo.

Em síntese, a intertextualidade envolve o exame da forma como outros textos são incorporados ao texto em análise, podendo ser: citação (direta ou indireta); afirmações modalizadas (epistêmica ou deôntica); afirmações não modalizadas; e pressupostos.

Observamos nos exemplos do Quadro 1 que, na modalidade mais dialógica da intertextualidade, a citação, o enunciante recorre de forma direta a um outro texto para apresentar uma ideia, qual seja, a incapacidade das instituições. O outro texto está incorporado de forma explícita em seu texto e, portanto, conserva aberto o diálogo. Nas afirmações modalizadas, a conexão da ideia do enunciante com outros textos (não com um texto específico, como na citação, mas com o mundo dos textos) não está encoberta, mas podemos observar que o engajamento do enunciante com a ideia (demonstrada pelos marcadores "nunca" e "tem que") diminui o diálogo. Já na afirmação não modalizada, ao afirmar "não vou apoiar algo que não consiga tangilibizar", não há diálogo. Para o enunciante a ideia da 
tangibilização dos resultados de projetos sociais é uma prerrogativa, e, a partir dessa posição denunciada pelo uso do marcador "não", há uma considerável diminuição da dialogicidade. E, por fim, o pressuposto suspende o diálogo pois toma ideias como dadas. No exemplo em questão, o artigo definido "a" que precede o substantivo "organização social" contribui em revelar que há uma ideia inculcada do que é uma organização social. Os pressupostos são mais dificilmente percebidos nos textos justamente por não representarem ideias explícitas e sim assumidas e, por isso, atuam inconscientemente na reprodução de discursos.

Quadro 1 - Exemplos de formas de intertextualidade

a) Citação: “'A pobreza não é resultado da incapacidade dos pobres e sim da deficiência das instituições'. É muito feliz essa frase, é a realidade em nós vivemos".

b) Afirmação modalizada (epistêmica): "Nunca coloque uma organização social numa posição caridosa, filantrópica".

c) Afirmação modalizada (deôntica): "A organização social, o empreendedor social, tem que olhar as forças do mercado".

d) Afirmação não modalizada: "a gente prefere projetos de menor duração, seis meses. Depois de seis meses, a instituição traz o resultado, mostra o que aconteceu e aí eu renovo. Não vou apoiar algo que não consiga tangilibizar".

e) Pressuposto: "O lucro social é o resultado que a organização social consegue promover através do seu trabalho".

Além da análise da intertextualidade, há duas importantes categoria de análise sugeridas por Fairclough (2003) para explorar, especificamente, o significado representacional: a interdiscursividade e a representação de eventos sociais.

\subsection{INTERDISCURSIVIDADE}

Um discurso pode se ligar a outros discursos numa relação dialógica harmônica ou polêmica. Essa heterogeneidade de um texto em termos da articulação de diferentes discursos é chamada interdiscursividade (FAIRCLOUGH, 2003). A análise interdiscursiva de um texto corresponde à identificação dos discursos articulados e da maneira como são articulados. Para identificar discursos em um texto, Fairclough (2003) aponta duas etapas: (1) identificar quais as principais partes do mundo que estão representadas (os temas tratados no texto) e (2) identificar a perspectiva particular, ou ponto de vista, pela qual são representadas.

As maneiras particulares de representação de aspectos do mundo podem ser especificadas por meio de traços linguísticos que podem ser vistos como 'realizando' um discurso. Segundo Fairclough, o mais evidente desses traços distintivos é o vocabulário, pois diferentes discursos 'lexicalizam' o mundo de maneiras diferentes. Assim, a análise do vocabulário fornece uma rica evidência, já que as escolhas lexicais para compor um texto são feitas de modo que uma ideia/representação específica de mundo possa ser transmitida. Neste sentido, importa identificar sinônimos, metáforas entre outros aspectos gramaticais 
que utilizamos na linguagem para expressar determinado ponto de vista que, por sua vez, revelam nossa posição sobre um determinado fenômeno.

Quadro 2 - Exemplo de análise de vocabulário

a) "Então, é um projeto inovador? É, só que baseado numa ideia existente que foi aperfeiçoada [...]. Que foi desenvolvido a partir da ideia de cowork tradicional para uma situação de público alvo diferenciada, que é implantar esse projeto nas comunidades menos favorecidas."

b.) "Então assim, os profissionais que atuam no terceiro setor tem que ter valorização, capacitação e profissionalização [...]".

Nos exemplos apresentados no Quadro 2 observamos que, as palavras destacadaspoderiam ser substituídas por muitas outras palavras possíveis. A exemplo disso, no trecho (a) onde está mencionado "comunidades menos favorecidas", outras tantas expressões poderiam ter sido empregadas, como: periferia, comunidades pobres, favela, bairros populares, comunidades desassistidas, bairros "barra pesada" etc. sendo que cada uma dessas opções lexicais revelaria uma visão de mundo distinta. Da mesma forma, as palavras sublinhas no trecho (b), "valorização, capacitação e profissionalização", poderiam ter sido outras tantas como, por exemplo: ética, solidariedade, rede de contatos, experiência. Portanto, a análise do vocabulário contribui para revelar a visão de mundo que é reproduzida em um determinado texto.

É importante observar que diferentes discursos podem usar as mesmas palavras, entretanto, com significados diferentes, representando diferentes conceitos sobre o mesmo fenômeno ou objeto. Fairclough (2003) indica que um modo de encontrar essas diferenças é através de colocações, padrões de co-ocorrência no texto, observando quais palavras mais frequentemente precedem ou seguem (ainda que não imediatamente) qualquer palavra que esteja em consideração.

Outro ponto de partida interessante para a análise do vocabulário é a investigação do recurso da metáfora. A metáfora, conforme nos explica Fairclough (2003), significa explicarmos uma coisa em função de outra. Assim, quando selecionamos uma metáfora para significar algo estamos construindo nossa realidade de maneira particular.

Quadro 3 - Exemplo de Metáfora (1)

"É sempre um desafio a gente encantar os patrocinadores [...] é trabalho difícil de a gente conseguir o primeiro contato, e manter também é uma tarefa que a gente tem que saber fazer, como a diz, é um namoro que a gente tem que manter com os patrocinadores, e isso a gente tem que fazer no dia a dia, mostrar o resultado, chamar esse patrocinador".

Analisando o exemplo apresentado no Quadro 3, percebemos que a expressão "namoro" é uma metáfora que no texto é usado para representar a relação das organizações sem fins lucrativos com seus patrocinadores. Essa metáfora nos indica que está em curso uma representação de mundo na qual existe uma relação desigual, que requer que as organizações sem fins lucrativos convençam permanentemente as empresas a manterem o patrocínio aos seus projetos sociais. Note que ao posicionar o patrocinador como 
um ator que tem que ser "encantado", e para o qual as organizações sem fins lucrativos devem direcionar atenção, sinaliza uma relação de poder assimétrica. 0 "namoro" implica um processo de conquista, no qual uma das partes se esforça pela atenção da outra, a qual assume uma posição de poder na relação. Dessa maneira, a representação de mundo expressa no texto reproduz uma realidade social marcada pela desigualdade de poderes na qual a empresa patrocinadora (representante do dinheiro) é superior a organização sem fim lucrativo (realizadora da ação social).

Quadro 4 - Exemplo de Metáfora (2)

"O administrador moderno precisa enxergar as ONGs como um braço eficiente que atua diretamente com a população necessitada. Nós temos essas características que as organizações sociais conhecem a realidade das pessoas no seu dia a dia, tá? As organizações políticas precisam entender que uma organização social pode ser o seu braço direito, tá? E com isso que a sociedade seja melhor atendida, tá?"

No segundo exemplo de metáfora, apresentado no Quadro 4, as metáforas "braço eficiente" e "braço direito" ao serem usadas para definir a relação das organizações sem fins lucrativos com o Estado, reproduzem o discurso do terceiro setor. Neste discurso, se preconiza a substituição do Estado por organizações sociais profissionalizadas para o trato da questão social, sob a justificativa de que o Estado é incapaz de fazê-lo, pois é demasiadamente burocrático e estas são supostamente mais ágeis e eficientes (MONTAÑO, 2010). Assim, no discurso do terceiro setor as organizações sem fins lucrativos cumprem um papel de complementação da atuação do Estado, tal como a metáfora braço representa no discurso reproduzido no texto.

A análise lexical contribui também para identificar o modo como os argumentos são desenvolvidos no texto, favorecendo a discussão sobre a questão da legitimação. A análise das estratégias de legitimação contribui para se identificar num texto a qual(is) discurso(s) é reproduzido, ou seja, quais os recursos o enunciante lança mão para validar uma representação particular. Segundo Fairclough (2003), com base em van Leeuwen e Wodak (1999), são quatro as principais estratégias de legitimação:

1. Autorização: legitimação através da referência à autoridade da tradição, costume, leis e de pessoas com algum tipo de autoridade institucional investida;

2. Racionalização: legitimação através da referência à utilidade da ação institucionalizada e ao conhecimento acumulado pela sociedade para conferir validade cognitiva;

3. Avaliação moral: legitimação através da referência ao sistema de valores;

4. Mitopoiesi: legitimação através da referência a depoimentos/narrativas convincentes. 
Quadro 5 - Exemplos de estratégias de legitimação

a) Autorização: "Tem um programa nos EUA, que se e tentou Brasil, mas que não funcionou, o "United Way" onde eles fazem isso: eles vão para as empresas e fazem desconto na folha de pagamento para as pessoas fazerem a doação, esse programa funciona maravilhosamente bem nos EUA e em alguns países da Europa. No Brasil não conseguiu funcionar."

b) Racionalização: "a avaliação dessas solicitações está centralizada aqui, nós temos um sistema de avaliação, nós temos um comitê de avaliação que nós chamamos de Comitê de Sustentabilidade, multidisciplinar, que avalia esses pedidos que vêm até nós, [...] as solicitações de patrocínio devem ser feitas através de um formulário padrão que vai direto para nossa comissão."

c) Avaliação moral: "levamos [empresa] alguns colaboradores para lá e que ficam a manhã inteira na instituição, almoçaram lá no refeitório onde as crianças almoçam aquele feijãozinho com arroz, e isso foi importante porque a gente aproximou o colaborador da instituição, que foi a instituição que teve maior volume de doações".

d) Mitopoiesi: "Sofia era uma jovem de 21 anos que lutava desesperadamente para sobreviver. Para poder trabalhar Sofia tinha tomado emprestado cerca de vinte e cinco centavos de dólar americano a um agiota de seu bairro, Jobra, [...] Yunus encontrou 42 mulheres em Jobra nas mesmas condições e resolveu ele mesmo emprestar-Ihes seu próprio dinheiro a taxas bancárias "normais. [...] Ele criou um banco de micro empréstimos".

Nos exemplos apresentados no Quadro 5, podemos observar o uso de diferentes estratégias para dar legitimidade a ideias ou ações. Observe no caso (a) que o enunciante recorreu à autorização para valorizar o programa mencionado (United Way), referenciando em seu texto locais onde houve êxito como Estados Unidos e Europa, mas que "no Brasil não conseguiu funcionar". Da mesma forma, podemos observar no exemplo (b), que o "comitê de avaliação" e o "formulário padrão" são recursos que conferem utilidade à ação e são, portanto, incorporados ao texto para conferir legitimidade ao modo de avaliação de projetos sociais. No exemplo (c), "almoçar o feijãozinho com arroz junto com as crianças", mobiliza valores morais para legitimar o discurso em curso, qual seja, a ação da empresa que sensibiliza seus funcionários a doarem parte de seu imposto de renda às instituições assistenciais. Por fim, no exemplo (d), uma história é contada (a de mulheres pobres que encontraram num banco de microcrédito uma alternativa de viabilizarem seus trabalhos) para legitimar a importância dos negócios sociais, pois é esta a tônica defendida pelo enunciante no texto do qual este trecho foi extraído.

\subsection{REPRESENTAÇ̃̃O DE EVENTOS SOCIAIS}

Além da interdiscursividade, outra importante categoria para análise do significado representacional é a representação de eventos sociais. Isto implica examinar a forma como os eventos são recontextualizados, ou seja, como um evento social é representado no contexto de outro evento. Neste processo, elementos de um evento social são seletivamente filtrados quando recontextualizados (algumas coisas são excluídas, incluídas, ganham maior ou menor projeção) o que afeta a forma como são representados. Conforme Fairclough (2003), alguns princípios orientam a recontextualização: 
1. Presença: elementos do evento que estão presentes ou ausentes, quais são destacados e quais ficam como pano de fundo;

2. Abstração: grau de abstração e generalização no tratamento de um evento concreto;

3. Arranjo: como os eventos são ordenados;

4. Adição: o que é acrescentado na representação do evento, explicações, legitimações (motivos, causas, propósitos), avaliações etc.

A recontextualização, portanto, interfere na maneira como eventos e atores sociais são representados em textos e pode revelar posicionamentos ideológicos em relação a eles e suas atividades. Para isso, o sistema de transitividade pode ser usado como uma ferramenta na análise textual a fim de revelar as escolhas linguísticas de um determinado texto. Segundo Fairclough (2001) uma motivação social para analisar a transitividade é tentar formular que fatores sociais, culturais, ideológicos, políticos ou teóricos determinam como um processo é significado num tipo particular de discurso.

O sistema de transitividade aponta as escolhas léxico-gramaticais que demonstram como a representação de mundo foi construída em determinado texto. A transitividade, portanto, é um importante recurso para entender as representações, pois nos permite identificar, nos textos, os processos, os participantes e as circunstâncias. Desse modo, a transitividade sinaliza nas frases as associações entre o que é realizado (processos) e os papeis atribuídos aos envolvidos (participantes) (EGGINS, 1994), em outras palavras, ajuda a entender: quem faz o que e em que circunstância?

$\mathrm{Na}$ análise da transitividade buscamos, a partir da identificação do verbo da oração, compreender o processo em curso (material, relacional, mental, verbal ou existencial) para então identificar os papeis assumidos/atribuídos aos participantes nesses processos e a circunstância em que ocorrem. 0 processo material representa nossa experiência no mundo exterior, ou seja, as ações realizadas no mundo físico. Nesse sentido, os processos materiais são responsáveis pela criação de uma sequência de ações concretas (HALLIDAY, 2004), sejam elas criativas ou de transformação. Todo processo material tem, obrigatoriamente, um agente (que realiza ação), mesmo que ele não seja explicitamente mencionado no texto. Opcionalmente, pode haver outros participantes, como um beneficiário (que é o atingido pela ação) ou uma meta (que é o resultado da ação).

Quadro 6 - Exemplo de Análise da Transitividade (Processo Material)

\begin{tabular}{|c|c|c|c|}
\hline \multicolumn{2}{|c|}{ "a partir da avaliação dos resultados econômicos e financeiros, nós fornecemos insumos para promo- } \\
ção de melhorias de desempenho no desenho do projeto" \\
\cline { 1 - 3 } Nós & Fornecemos insumos & $\begin{array}{c}\text { Para promoção de melho- } \\
\text { rias de desempenho no } \\
\text { desenho do projeto }\end{array}$ & $\begin{array}{c}\text { Da avaliação dos resultados } \\
\text { econômicos e financeiros }\end{array}$ \\
\cline { 1 - 3 } [organização] & Processo Material & Meta & Circunstância de modo \\
\hline
\end{tabular}

Observamos que, no exemplo trazido no Quadro 6, há uma crença sustentada no texto de que a avaliação (econômica e financeira) é o modo de melhorar o desempenho do 
projeto social, e essa avaliação é feita pela própria organização social. Nesse caso, podemos perceber que o texto reproduz uma ideia de que o sucesso de um projeto social pode ser verificado a partir dos seus resultados econômico-financeiros, e não a partir da percepção do público alvo, que é um ator suprimido do processo.

$\mathrm{Na}$ análise da transitividade um outro tipo de processo é o relacional, sendo útil para indicar a relação entre os participantes. A relação entre estes participantes pode ser de modo atributivo, em que A é um atributo de B (o portador e o atributo); ou identificativo, em que $A$ é a identidade de $B$ (identificador e identificado).

O importante é observar que o processo relacional possui uma função classificatória dos participantes e a partir desta análise podemos identificar como eles são classificados e caracterizados num dado discurso. Ao utilizar este recurso discursivo o texto se compromete com uma visão de mundo.

Quadro 7 - Exemplo de Análise da Transitividade (Processo Relacional)

“A organização social é uma empresa que tem missão de resolver um problema social"

\begin{tabular}{|c|c|c|}
\hline A organização social & é & uma empresa \\
\hline Identificado & Processo relacional & Identificador \\
\hline
\end{tabular}

No exemplo do Quadro 7, o enunciante ao representar em seu texto as organizações sem fins lucrativos, estabelece uma relação entre organização social (identificado) e empresa (identificador). No entanto, é importante observar que a noção de empresa, que corresponde a uma forma entre as múltiplas possibilidades de formas organizacionais, está pautada na ideologia do management (PARKER, 2002). O discurso do managerialism percebe as organizações como objetos semelhantes que podem ser otimizadas pela aplicação de habilidades gerenciais (KLIKAUER, 2015). Assim, podemos dizer que o texto contribui na manutenção de uma visão dominante de mundo na qual organização é sinônimo de empresa e, desta forma, questões típicas da gestão estratégica (como o alcance de metas; a aplicação eficaz dos recursos; e a tomada racional de decisão) passam a ser aspectos valorizados mesmo em organizações sem finalidade lucrativa. Neste contexto, tudo que está em desacordo com este modelo ideal de organização é reconhecido como "deficiência" e deve ser solucionado pelos mecanismos da gestão privada.

Ainda na análise da representação dos eventos sociais, as nominalizações também são incluídas como uma importante categoria para análise da dimensão representacional. Segundo Fairclough (2003), na nominalização processos são apresentados como entidades agindo como um recurso de generalização e abstração de eventos particulares. Em relação a este recurso, quando há um processo de nominalização em representações, pode-se ocultar o agente, causando generalização, assim como abstração de processos, e, portanto, eliminando ações de agentes. Igualmente, a questão de responsabilidade também é omitida, uma vez que não existe um ator envolvido em algum tipo de ação (FAIRCLOUGH, 2003). 
Quadro 8 - Exemplo de Nominalização (1)

"Bem, da avaliação, nós vamos determinar se a gestão e operação do projeto são eficazes. Então muitas vezes, o projeto não tem culpa, quem tem culpa é a gestão, tá?"

No primeiro exemplo de nominalização, destacado no Quadro 8, notamos que a gestão é tratada como uma entidade responsável pela ineficácia organizacional. Assim, a gestão é tomada como uma entidade que pode ser responsabilizada por algo, quando na verdade trata-se da ação de indivíduos. Então o processo de nominalização, nesse caso, é útil para desresponsabilizar os agentes ao suprimi-los da representação dos eventos sociais.

Quadro 9 - Exemplo de Nominalização (2)

"Tem dinheiro, tem orçamento, e a burocracia, por uma série de motivos, não deixa que esse dinheiro seja investido. Nós temos que cuidar para não fazer isso também no terceiro setor. $\mathrm{Na}$ área social, a gente tem que evitar essa burocracia que tem acontecido muito no setor público."

No Quadro 9, o trecho "a burocracia [...] não deixa" é um outro exemplo de nominalização. A burocracia é uma entidade abstrata e, portanto, quem deixa ou não algo acontecer são indivíduos. Ao representar a burocracia desta forma parece que este é um fenômeno natural e não efeito de construções sociais. Deste feito, a burocracia é representada como a própria responsável pelos problemas em termos de investimentos sociais, situação para a qual parece não haver indivíduos responsáveis, sendo apontada como uma condição permanente. Assim, a alternativa apresentada no texto de onde este trecho foi extraído é tratar as organizações sem fins lucrativos como "braço eficiente" do Estado, conforme destacamos anteriormente, evidenciando uma vinculação do texto ao discurso do Terceiro Setor.

Em síntese, o que buscamos fazer nessa seção foi exemplificar categorias analítica indicadas para operacionalizar o significado representacional. Neste sentido, apresentamos a intertextualidade, a interdiscursividade e a representação de eventos sociais.

\section{CONSIDERAÇÕES FINAIS}

Embora a adoção da Análise Crítica do Discurso na Administração não seja nova, seu uso ainda é restrito e a análise da dimensão textual nem sempre tem sido explorada em profundidade. Neste trabalho, enfatizamos o potencial desta proposta teórico-metodológica para os estudos organizacionais críticos, bem como fornecemos subsídios para operacionalizar categorias analíticas do significado representacional, procurando elucidar aspectos relacionados à análise linguística dos textos com vistas a disseminar a abordagem entre pesquisadores do campo.

Como destacado, a ACD é uma abordagem sociodiscursiva que busca explicar fenômenos sociais apoiada em evidências empíricas linguísticas. Assim, a análise do texto é um momento imprescindível da abordagem. Fairclough $(2001,2003)$ é enfático ao sinalizar que, apesar da ACD não se restringir apenas a análise textual, o texto é um momento 
essencial no método. Para Halliday (2004), uma análise do discurso não resguardada por evidências linguísticas é apenas uma opinião, ou seja, o texto é a evidência empírica da análise que subsidia as argumentações da pesquisa, as quais devem ter um engajamento crítico, a fim de manter coerência epistemológica com a abordagem.

Enfatizamos que a Análise Crítica do Discurso pressupõe uma estrutura analítica mais ampla do que a análise textual propriamente dita. Apesar da contribuição indispensável da análise textual, ela guarda apenas um poder descritivo já que o domínio explicativo do fenômeno em análise está contido na análise da prática social. Assim, é nesta dimensão que se busca explicar as formas de ideologia e hegemonia contidas no discurso. 0 quadro analítico da ACD envolve, portanto, o reconhecimento de um problema social que tenha um aspecto semiótico; a identificação de obstáculos para que esse problema seja resolvido (etapa que envolve a análise linguística); reconhecer maneiras possíveis para superar os obstáculos; e, por fim, refletir criticamente sobre a análise (CHOULIARAKI; FAIRCLOUGH, 1999). Reiteramos, portanto, o potencial da Análise Crítica do Discurso para estudos organizacionais engajados no ato da denúncia (FREIRE, 2001) e uma análise detalhada de textos, na perspectiva representacional, tem potencial significativo nesse processo.

Na ACD parte-se do princípio que, de forma geral, os indivíduos não têm consciência do papel que o discurso exerce no controle e modelagem da vida social. Sendo assim, a análise do discurso com orientação crítica se presta a revelar questões ideológicas sustentadas pelos discursos, porém não conscientes para as pessoas em suas práticas sociais. Dessa maneira, a tarefa da ACD "implica mostrar conexões e causas que estão ocultas" e lutar pela emancipação (FAIRCLOUGH, 2001, p. 28). Neste sentido, o caráter emancipatório da ACD fundamenta-se em sua proposta central de revelar o conteúdo ideológico dos discursos. Ao se expor as ideologias subjacentes a um discurso, se contribui para conscientizar as pessoas de que nem tudo que é senso comum é natural, mas sim naturalizado por tradições e convenções sociais que, normalmente, perpetuam relações assimétricas de poder. Dessa forma, quando as práticas discursivas são percebidas como construções sociais podem ser questionadas e perder a força de sustentar práticas sociais centradas na desigualdade abrindo espaço para intervenção, proporcionando aos indivíduos, em desvantagem, recursos para mudança.

\section{REFERÊNCIAS}

AGUIAR, A. R. C.; CARRIERI, A. P. 'Água de lona' e 'sangue de serragem' nos discursos de sujeitos circenses. Organizações \& Sociedade, v. 23, n. 77, p. 247-262, 2016.

AUGUSTINIS, V. F.; COSTA, A. S. M.; BARROS, D. F. Uma análise crítica do discurso de educação financeira: por uma educação para além do capital. Revista ADM.MADE, v. 16, n. 3, p. 79-102, 2012.

BORGES, J. F.; VALADÃO JÚNIOR, V. M. A construção do sentido e a retórica das empresas na web. Cadernos EBAPE.BR, v. 6, n. 1, p. 1-21, 2008.

BRANDÃO, H. H. L. Introdução à análise do discurso. Campinas: Editora Unicamp, 2004. 
BRETAS, P. F. F.; SARAIVA, L. A. Discursos e sentidos da participação popular em um centro de saúde de Belo Horizonte. Revista Eletrônica de Ciência Administrativa, v. 13, n. 2, p. 203-218, 2014.

CARRIERI, A. P.; SOUZA, E. M.; AGUIAR, A. R. C. Trabalho, violência e sexualidade: estudo de lésbicas, travestis e transexuais. Revista de Administração Contemporânea, v. 18, n. 1 , p. 78-95, 2014.

CHOULIARAKI, L.; FAIRCLOUGH, N. Discourse in late modernity. Rethinking critical. Edinburgh: Edinburgh University Press, 1999.

COSTA, A. S. M.; BARROS, D. F.; MARTINS, P. E. M. A alavanca que move o mundo: 0 discurso da mídia de negócios sobre o capitalismo empreendedor. Cadernos EBAPE.BR, v. 10, n. 2, p. 357-375, 2012.

CUNHA, M. A.; COELHO, T. R.; POZZEBON, M. Internet e participação: o caso do orçamento participativo digital de Belo Horizonte. Revista de Administração de Empresas, v. 54, n. 3, p. 296-308, 2014.

DOURADO, D. C. P.; CARVALHO, C. A. Extra! Extra! O caso do Metrorec revela como é operada a manipulação ideológica do discurso da QVT. Cadernos EBAPE.BR, v. 5, n. 4, p. 1-16, 2007.

EGGINS, S. An Introduction to Systemic Functional Linguistics. London: Pinter, 1994.

FAIRCLOUGH, N. Language and Power. New York: Longman, 1989.

Discurso e Mudança Social. Tradução de Izabel Magalhães. 1. ed. Brasília: Universidade de Brasília, 2001.

Analyzing Discourse: textual analysis for social research. London: Routledge, 2003.

FARIA, J. H. Teoria crítica em estudos organizacionais no Brasil: o estado da Arte. Cadernos EBAPE. BR, v. 7, n. 3, Rio de Janeiro, 2009.

FRANCO, S. M.; LEÃO, A. L. M. S. As "marcas" de uma nova fronteira vinícola: identidade cultural das marcas de vinhos do Vale do São Francisco. Revista Eletrônica de Ciência Administrativa, v. 13, n. 3, p. 393-413, 2014.

FREIRE, P. Conscientização: teoria e prática da libertação - uma introdução ao pensamento de Paulo Freire. São Paulo: Centauro, 2001.

FREITAS, R. C. et al. Relações Interorganizacionais em Grupos de Pequenos Produtores Familiares no Sul de Minas Gerais: Reflexões Críticas e Inovações Sociais. Organizações Rurais \& Agroindustriais, v. 18, n. 1, p. 39-51, 2016.

HALLIDAY, M. An introduction to functional grammar. 3. ed. London: Arnold, 2004.

HARVEY, D. Condição pós-moderna. São Paulo: Edições Loyola, 2003.

KLIKAUER, T. Managerialism: A critique of an ideology. London: Palgrave Macmillan, 2015.

LACERDA, D. S.; BRULON, V. Política das UPPs e espaços organizacionais precários: uma análise de discurso. Revista de Administração de Empresas, v. 53, n. 2, p. 130-141, 2013. 
MACEDO, A. S.; ALCÂNTARA, V. C.; PEREIRA, J. R. A Incorporação das Dimensões Sociais e Ambientais no Novo Marco Regulatório da Mineração sob a Ótica da Gestão Social. Amazônia, Organizações e Sustentabilidade, v. 4, n. 1, p. 151-172, 2015.

MELO, P. T. N. B.; SALLES, H. K.; VAN BELLEN, H. M. Quadro institucional para o desenvolvimento sustentável: o papel dos países em desenvolvimento com base na análise crítica do discurso da Rio+20. Cadernos EBAPE.BR, v. 10, n. 3, p. 701-720, 2012.

MEURER, J. L. Gêneros textuais na análise crítica de Fairclough. In: MEURER, J. L.; BONINI, A.; MOTTA-ROTH, D. Gêneros: teorias, métodos, debates. São Paulo: Parábola, 2005.

MISOCZKY, M. C. Análise crítica do Discurso: uma apresentação. GESTÃO.Org - Revista Eletrônica de Gestão Organizacional, v. 3, n. 2, p. 125-140, 2005.

MISOCZKY, M. C. O Banco Mundial e a reconfiguração do campo das agências internacionais de saúde: uma análise multiparadigmática. Revista de Administração Pública, v. 37 , n. 1, p. 75-97, 2003.

MISOCZKY, M. C.; FERRREIRA, C. S. A construção simbólica da definição de governar e de governador realizada pelo jornal Zero Hora nas três últimas eleições gaúchas. Cadernos EBAPE.BR, v. 3, n. 4, p. 1-17, 2005.

MONTAÑO, C. Terceiro setor e questão social: crítica ao padrão emergente de intervenção social. 6. ed. São Paulo: Cortez, 2010.

ONUMA, F. M. S.; ZWICK, E.; BRITO, M. J. Ideologia Gerencialista, Poder e Gestão de Pessoas na Administração Pública e Privada: uma interpretação sob a ótica da Análise Crítica do Discurso. Revista de Ciências da Administração, v. 17, n. 42, p. 106-120, 2015.

RODRIGUES, M. S.; DELLAGNELO, E. H. L. Do discurso e de sua análise: reflexões sobre limites e possibilidades na Ciência da Administração. Cadernos EBAPE.BR, v. 11, n. 4, p. 621-621, 2013.

ROSA FILHO, D. S. Poder simbólico no reajuste tarifário do transporte metropolitano de passageiros de Porto Alegre na crise de 2004. Revista de Administração Pública, v. 45, n. 3, p. 643-668, 2011.

SALLES, H. K. et al. Mercantilização de ações solidárias empresariais: uma discussão a partir da análise crítica do discurso. GESTÃO.Org - Revista Eletrônica de Gestão Organizacional, v. 9, n. 2, p. 226-253, 2011.

SANTOS, B. D. S. Para uma sociologia das ausências e uma sociologia das emergências. Revista Crítica de Ciências Sociais, Coimbra, p. 237-280, 2002.

SCHARF, E. R.; SARQUIS, A. B. Análise crítica do discurso na propaganda de lançamento do Citroën C3 Picasso. Revista Brasileira de Marketing, v. 13, n. 3, p. 36-48, 2014.

SILVA, M. A. C.; COSTA, A. S. M.; LEMOS, A. H. C. A Discriminação Certificada: O Discurso da Revista Você S.A. sobre a Obrigatoriedade da Pós-Graduação para Inserção no Mercado de Trabalho. Revista Pensamento Contemporâneo em Administração, v. 9, n. 1, p. 16-34, 2015. 
VALADÃO JUNIOR, V. M.; MEDEIROS, C. R. O.; LIMA, M. C. Peter Drucker e a legitimação do capitalismo tardio: uma análise crítica de discurso. GESTÃO.Org - Revista Eletrônica de Gestão Organizacional, v. 5, n. 3, p. 1-24, 2007.

VAN LEEUWEN, T.; WODAK, R. Legitimizing Immigration Control: A Discourse-Historical Analysis. Discourse Studies. v. 1, n. 1, p. 83-118, 1999.

Data de Submissão: 06/12/2016.

Data de Aprovação: 20/12/2017. 